\title{
Metabolismo oxidativo e perfil bioquímico de ovelhas santa inês no período periparto: efeito da suplementação parenteral com vitamina $\mathbf{E}$
}

\section{Oxidative metabolism and biochemistry profile of santa ines sheep in periparturition: effect of parenteral vitamin $E$}

\author{
Priscilla Marques do Nascimento ${ }^{1}$; Aline Alberti Morgado ${ }^{1}$; Giovanna Rocha \\ Nunes ${ }^{1}$; João Paulo Nikolaus²; Rebeca Alves Weigel ${ }^{1}$; Alessandra Silva Lima ${ }^{1}$; \\ Vanessa Martins Storillo ${ }^{1}$; Clara Satsuki Mori³ ${ }^{3}$ Maria Claudia Araripe Sucupira ${ }^{4 *}$
}

\section{Resumo}

Foram utilizadas 14 ovelhas Santa Inês, hígidas, no último mês de gestação que receberam duas aplicações de solução fisiológica (grupo controle-GC), ou $200 \mathrm{mg}$ de acetato de $\alpha$-tocoferol (vitamina E) (grupo tratado-GT), com intervalo de 14 dias, aos 21 e de 1 a 7 dias antes do parto, respectivamente para a primeira e segunda doses. As amostras de sangue foram coletadas previamente à primeira aplicação (M0), duas semanas após a primeira aplicação (M1), no parto (M2), uma semana (M3), duas semanas (M4) e quatro semanas após o parto (M5). Foram analisadas as concentrações de proteína total, albumina, globulina, ureia, creatinina, ácido úrico, colesterol, triglicérides, glicose, beta hidroxibutirato (BHB), ácidos graxos não esterificados (AGNEs); e as atividades séricas de creatinofosfoquinase (CK), aspartatoaminotransferase (AST) e gamaglutamiltransferase (GGT). Do metabolismo oxidativo foram determinadas as atividades da superóxido dismutase (SOD), glutationa peroxidase (GSH-Px), glutationa reduzida (GSH) e habilidade de redução férrica plasmática (HRFP). Não foram observadas diferenças entre GT e GC nas concentrações de proteína total, globulinas, CK, ácido úrico, glicose, triglicérides, BHB, AGNES, SOD, GSH-Px e GSH. Porém foram observadas maiores concentrações de albumina em M0 ( $\mathrm{P}=0,039)$; ureia em M1 $(\mathrm{P}=0,018), \mathrm{M} 2(\mathrm{P}=0,005)$ e $\mathrm{M} 3(\mathrm{P}=0,040)$; creatinina em M2 $(\mathrm{P}=0,030)$ e M3 ( $\mathrm{P}=0,047)$; GGT em M1 ( $\mathrm{P}=0,01)$ e M2 $(\mathrm{P}=0,024)$, colesterol em M2 ( $\mathrm{P}=0,041)$ e HRFP em M3 $(\mathrm{P}=0,022)$ para GT em relação ao GC. A AST foi maior para o GC em relação ao GT em M2 ( $\mathrm{P}=0,030)$. A aplicação de vitamina E (200 UI, via IM) aumentou a HRFP no pós-parto.

Palavras-chave: Antioxidante, perfil metabólico, ruminantes

\begin{abstract}
Fourteen healthy Santa Inês sheep, in the last month of pregnancy, were used. They were divided into two groups who received or two injections of saline solution (control group - CG), or $200 \mathrm{mg}$ of $\alpha$-tocopherol acetate (vitamin E) (treated group - TG) with range of 14 days at 21 and 1 to 7 days before delivery, respectively, to the first and second doses. Blood samples were collected prior to the first application (T0) two weeks after the first application (M1), at delivery (M2), one week (M3), two
\end{abstract}

\footnotetext{
Pós-graduanda, Faculdade de Medicina Veterinária e Zootecnia da Universidade de São Paulo, FMVZ/USP, São Paulo, SP. E-mail: pm_nascimento@hotmail.com; aline.morgado@usp.br; giovannarocha@hotmail.com rebec@usp.br; alsvinhedo@ hotmail.com; veterinariavanessa@yahool.com.br

2 Discente, FMVZ/USP, São Paulo, SP. E-mail: jpnikolaus@gmail.com

3 Técnica de Laboratório, FMVZ/USP, São Paulo, SP. E-mail: clarasat@usp.br

4 Prof ${ }^{a}$, FMVZ/USP, São Paulo, SP. E-mail: msucupir@usp.br

Autor para correspondência
} 
weeks (M4) and four weeks after birth (M5). We analyzed the concentrations of total protein, albumin, globulin, urea, creatinine, uric acid, cholesterol, triglycerides, glucose, beta-hydroxybutyrate (BHB), non esterified fatty acids (NEFA), and the activities of serum creatine kinase (CK), aspartate (AST) and gamma glutamyl transferase (GGT). Oxidative metabolism were valued by activities of superoxide dismutase (SOD), glutathione peroxidase (GSH-Px), reduced glutathione (GSH) and ferric reducing ability of plasma (FRAP). No differences were observed between TG and CG in the concentrations of total protein, globulin, CK, uric acid, glucose, triglycerides, BHB, NEFA, SOD, GSH-Px and GSH. However, higher concentrations were observed in $\mathrm{M} 0$ for albumin $(\mathrm{P}=0.039)$; urea at $\mathrm{M} 1(\mathrm{P}=0.018)$, $\mathrm{M} 2(\mathrm{P}=0.005)$ and $\mathrm{M} 3(\mathrm{P}=0.040)$, creatinine at $\mathrm{M} 2(\mathrm{P}=0.030)$ and $\mathrm{M} 3(\mathrm{P}=0.047)$, GGT at $\mathrm{M} 1(\mathrm{P}=$ $0.01)$ and $\mathrm{M} 2(\mathrm{P}=0.024)$, cholesterol in $\mathrm{M} 2(\mathrm{P}=0.041)$ and FRAP in $\mathrm{M} 3(\mathrm{P}=0.022)$ for TG compared to CG. AST was higher for CG compared to TG in M2 $(\mathrm{P}=0.030)$. The application of vitamin $\mathrm{E}(200$ IU, IM) increased postpartum FRAP.

Key words: Antioxidant, metabolic profile, ruminants

\section{Introdução}

As principais doenças metabólicas que afetam pequenos ruminantes ocorrem no período periparto (CELI, 2010), principalmente nas últimas semanas de gestação. Estas enfermidades ocorrem devido ao aumento da exigência nutricional da ovelha decorrente do desenvolvimento fetal e início da produção de leite (OLIVEIRA et al., 2008).

Para esta adaptação homeorrética ocorre intenso processo metabólico associado, sobretudo à modificação do metabolismo energético e ao maior consumo de oxigênio. Assim, essa fase é apontada como período fisiológico favorável para o estresse oxidativo (GRUMMER, 1993; GOFF; HORST, 1997; DRACKLEY, 1999; BERNABUCCI et al., 2002). Esta condição é decorrente do desequilíbrio entre o status das substâncias antioxidantes e as espécies reativas de oxigênio (ERO's), em favor destas últimas.

Dependendo da intensidade deste processo, podem ocorrer danos moleculares às estruturas celulares, com consequente alteração e prejuízo das funções vitais (DRÖGE, 2002; RIBEIRO; GONZÁLEZ, 2003; HALLIWELL; GUTTERIDGE, 2007; WEIGEL, 2008). De acordo com Miller, Brzezinska-Slebodzinska e Madsen (1993), em ruminantes, o estresse oxidativo pode estar envolvido em diversas condições patológicas, incluindo aquelas mais relevantes para a reprodução, produção e bem-estar geral.
Isto posto, nas condições onde sabidamente ocorre aumento do metabolismo oxidativo a utilização de antioxidantes exógenos pode ser importante para prevenir ou minimizar o desequilíbrio. Dentre as substâncias antioxidantes exógenas, merece destaque o acetato de $\alpha$-tocoferol (HIDIROGLOU; KARPINSKI, 1987), a forma mais utilizada da vitamina $\mathrm{E}$.

O presente trabalho teve por objetivo avaliar o efeito no perfil bioquímico e nos marcadores de estresse oxidativo da suplementação parenteral da vitamina E no período periparto de ovelhas Santa Inês hígidas.

\section{Material e Métodos}

O presente estudo encontra-se dentro dos princípios éticos de experimentação animal da Comissão de Bioética da Faculdade de Medicina Veterinária e Zootecnia da Universidade de São Paulo, protocolo número 1708/2009.

Foram utilizadas 14 ovelhas, com média de 74 $\mathrm{kg}$ de peso vivo, da raça Santa Inês, hígidas, no último mês de gestação e mantidas nas dependências do Sistema Intensivo de Produção de Ovinos e Caprinos do Departamento de Produção Animal da Escola Superior de Agricultura "Luíz de Queiroz", campus de Piracicaba/SP (22\%43'31" latitude sul, altitude $550 \mathrm{~m})$. O experimento foi conduzido nos meses de outubro a dezembro de 2010 e, durante esse período, os animais foram mantidos sob o mesmo manejo alimentar (Tabela 1). 
Tabela 1. Composição da dieta de ovelhas suplementadas ou não com vitamina e durante o período experimental São Paulo/2012.

\begin{tabular}{lc}
\hline Composição da dieta & $\% \mathrm{MS}$ \\
\hline Bagaço de cana-de-açúcar & 30,00 \\
Milho & 45,10 \\
Farelo de Soja & 13,00 \\
Casca de soja & 9,80 \\
Ureia & 0,60 \\
Calcário & 0,50 \\
Mistura mineral* & 1,00 \\
\hline
\end{tabular}

*Composição do suplemento mineral :P 5,5\%; Ca 22\%; Mg 3,5\%; S 2,2\%; Na 7,0\%; Fe 500 ppm; Cu 450 ppm; Zn 1550 ppm; Se 20ppm.

Composição bromatológica: Matéria Seca: 75,5\%, Proteína Bruta: 13,7\%MS, Extrato étereo: 2,9\%MS, Fibra em detergente neutro: 44,8\%MS, Energia metabolizável, Mcal/kg de MS: 2,6\%MS.

Fonte: Elaboração dos autores.

As ovelhas foram distribuídas aleatoriamente formando dois grupos. O grupo controle (GC), composto por sete ovelhas, recebeu aplicação de 2,0 $\mathrm{mL}$ de placebo (solução fisiológica a $0,9 \%$ ) pela via intramuscular profunda (IM), e o grupo tratado (GT), composto por sete ovelhas recebeu, por via IM, $2 \mathrm{~mL}$ de produto comercial (Monovin $\mathrm{E}^{\circledR}$, laboratório BRAVET) contendo acetato de $\alpha$-tocoferol na concentração de $100 \mathrm{mg}$ (ou $100 \mathrm{UI}$ ) por mililitro de produto. Todas as ovelhas receberam duas aplicações ou de vitamina ou de placebo, com intervalo de 14 dias entre as aplicações, sendo a segunda dose administrada entre 1 e 7 dias antes do parto. As coletas de sangue foram realizadas aos 21 dias antes do parto (M0); 1 a 7 dias antes do parto (M1); no dia do parto (M2); uma semana (M3); duas semanas (M4); e quatro semanas após o parto (M5).

Para avaliar operfil bioquímico foram mensuradas as concentrações plasmáticas (plasma fluoretado) de glicose (kit Dyasis ${ }^{\circledR}$ - código 1.2500.99.10.022), betahidroxibutirato (BHB) (kit Randox ${ }^{\circledR}$ - código RB 1007) e ácidos graxos não esterificados (AGNES) (kit comercial Wako ${ }^{\circledR}$ ); as concentrações séricas de proteína total (método do biureto), albumina (método do verde bromocresol), ácido úrico (kit ByoSystems ${ }^{\circledR}$ - código 11521), colesterol (kit Biosystems ${ }^{\circledR}$ - código 11.505), triglicérides (kit Biosystems $^{\circledR}$ - código 11.529), ureia (kit Diasys ${ }^{\circledR}-$ código 1.3101.99.10.022) e creatinina (kit Labtest ${ }^{\circledR}$ - código 96-300); e as atividades séricas de aspartato aminotransferase (AST) (kit Biosystems ${ }^{\circledR}$ - código 11.531), gamaglutamil transferase (GGT) (kit Diasys ${ }^{\circledR}$ - código 1.280199.10.021) e creatinoquinase (CK) (kit Dyasis ${ }^{\circledR}$ - código 1.1601.99.10.021). Para avaliar o metabolismo oxidativo, foram determinadas as concentrações de glutationa reduzida (GSH) (BEUTLER; DURON; KELLY, 1963); habilidade de redução férrica plasmática (HRFP) (BENZIE; STRAIN,1996); atividades eritrocitárias da glutationa peroxidase (GSH - Px) (kit Randox ${ }^{\circledR}$ Ransel - código RS 505, papa de hemácias na diluição de $200 \mu 1$ ) e da superóxido dismutase (SOD) (kit Randox ${ }^{\circledR}$ Ransod - código SD 125, papa de hemácias na diluição de $200 \mu 1)$. A concentração de globulina foi obtida por meio da diferença entre as concentrações de proteína total e albumina (proteína total - albumina = globulina).

Para a obtenção dos eritrócitos (papa de hemácias), o sangue heparinizado foi centrifugado por 10 minutos em $450 \mathrm{G} \mathrm{a} 4^{\circ} \mathrm{C}$. As hemácias foram então lavadas com PBS por três ciclos para a obtenção da papa que foi armazenada por prazo máximo de 30 dias a $-80^{\circ} \mathrm{C}$, para posterior determinação das concentrações de superóxido dismutase (SOD) e atividade da glutationa peroxidase (GSH-Px). 
Exceto para as análises de GSH, cuja técnica é manual, as demais determinações foram realizadas em analisador bioquímico automático marca LABTEST $^{\circledR}$, modelo LABMAX 240.

Para realização da análise estatística, foi utilizado o software estatístico MINITAB ${ }^{\circledR}$, versão 14.1 (GlobalTech Informática $^{\mathrm{TM}}$, Belo Horizonte, $\mathrm{MG})$. As variáveis inicialmente foram submetidas ao teste de KOLGOMOROV \& SMIRNOV para verificar se os dados apresentavam distribuição paramétrica. Quando a distribuição foi não paramétrica, as variáveis foram analisadas pelo Teste não-paramétrico de Mann-Whitney. E quando as variáveis apresentaram distribuição normal, os dados foram submetidos inicialmente ao Teste $\mathrm{F}$ (ANOVA). Quando significativo, as médias foram comparadas pelo teste multiple-range de Tukey, com 5\% de significância. Foram consideradas significantes quando $\mathrm{P} \leq 0,05$.

\section{Resultados}

Como a distribuição das ovelhas foi realizada no terço final de gestação, não foi possível a separação dos grupos por número de fetos e a vitamina foi administrada baseada na data estimada de parto. Em média as ovelhas do GC receberam a segunda aplicação de solução fisiológica 3,4 $( \pm 1,0)$ dias antes do parto e as do GT receberam a vitamina E 4,0 ( \pm $1,5)$ dias. No GC, $86 \%$, e no GT, $43 \%$ das ovelhas apresentarem gestação gemelar, esta diferença não foi significante $(\mathrm{P}=0,096)$ entre os grupos. $\mathrm{O}$ peso médio dos cordeiros do grupo controle foi de 3,65 $\mathrm{kg}( \pm 0,69 \mathrm{~kg})$ e o do grupo tratado foi de $4,21 \mathrm{~kg}$ ( \pm $0,81 \mathrm{~kg})(\mathrm{P}=0,103)$.

Os valores de proteína total, CK, ácido úrico, globulina (Tabela 2), glicose, triglicérides, BHB, AGNES (Tabela 3), SOD, GSH e GSH-Px (Tabela 4) não diferiram entre GC e GT.

As ovelhas do GT apresentaram, em relação às do $\mathrm{GC}$, maiores concentrações séricas de albumina em M0 $(\mathrm{P}=0,039)$ (Tabela 2); de ureia em M1 $(\mathrm{P}=0,018), \mathrm{M} 2(\mathrm{P}=0,005)$ e $\mathrm{M} 3(\mathrm{P}=0,040)$ (Tabela 2); de creatinina em M2 ( $\mathrm{P}=0,030)$ e M4 $(\mathrm{P}=0,047)$ (Tabela 2); de GGT no M1 $(\mathrm{P}=0,011)$ e M2 $(\mathrm{P}=0,024)$ (Tabela 2); de colesterol no M2 ( $\mathrm{P}=$ 0,041) (Tabela 3); e HRFP apenas em M3 ( $\mathrm{P}=0,022)$ (Tabela 4). A atividade da enzima AST foi maior no GC no M2 ( $\mathrm{P}=0,030)$ (Tabela 2$)$.

\section{Discussão}

A aplicação parenteral de $200 \mathrm{mg}$ de acetato de alfa tocoferol (equivalente a $200 \mathrm{UI}$ ) não interferiu nas concentrações séricas de proteína total, globulina, ácido úrico, glicose, triglicerídeos, BHB e AGNEs e nem na atividade sérica de CK. Esta dose foi utilizada, baseada tanto em relação à equivalência apenas da vitamina $\mathrm{E}$ nas recomendações comerciais de compostos contendo a associação das vitaminas A, D e E, como também, considerando os resultados de trabalhos desenvolvidos por nosso grupo de pesquisa (STORILLO, 2012; LIMA, 2013). 


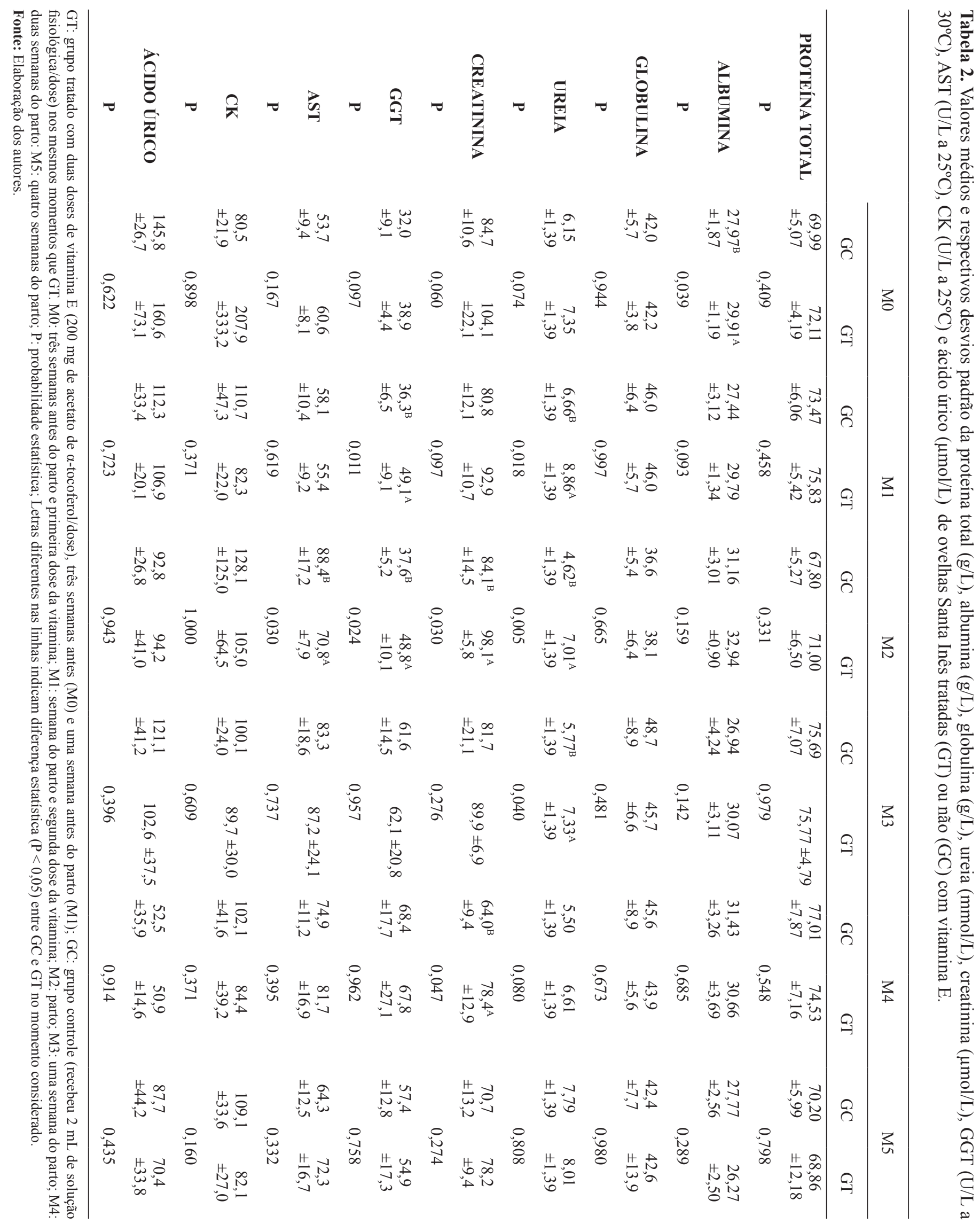




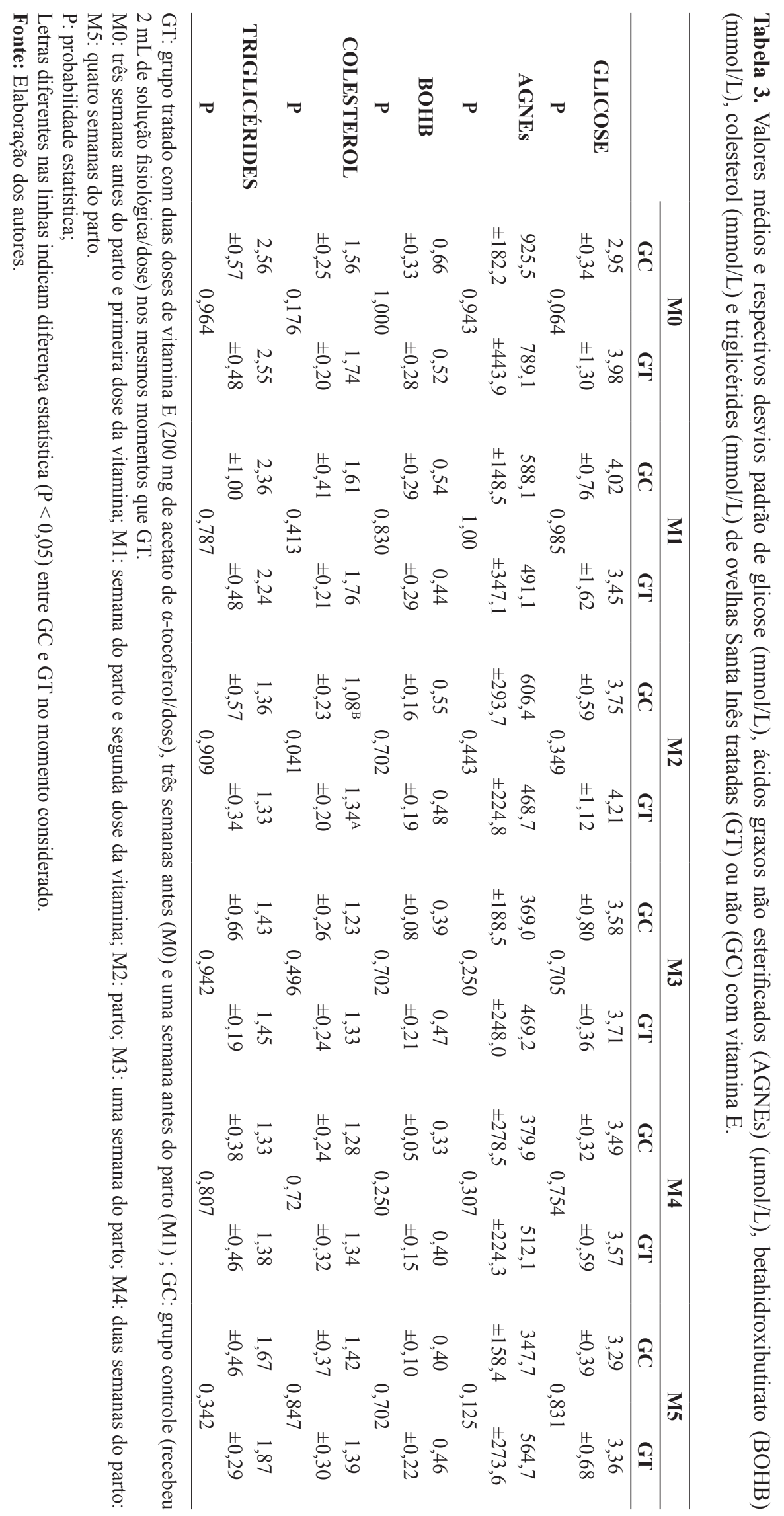




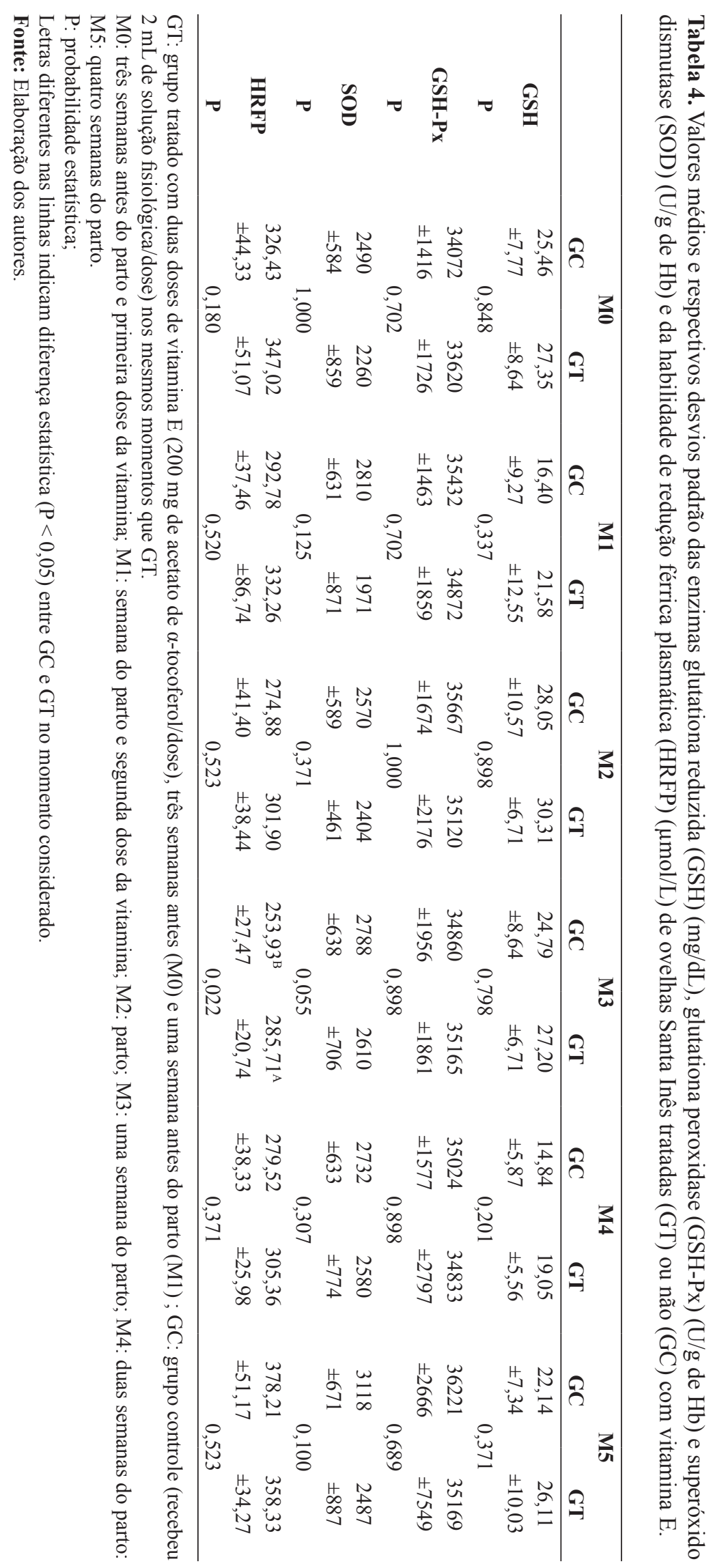


Durante o período estudado, os valores de proteína total ficaram dentro dos valores fisiológicos para a espécie (60-79 g/L) (KANEKO; HARVEY; BRUSS, 1997). Apesar das ovelhas terem mobilizado reservas corporais, estas não foram de grande magnitude, o que justifica a relativa estabilidade da proteína total entre os grupos. De maneira geral, esta variável é considerada indicador da homeostase proteica de longo prazo, e a ureia o indicador de curto prazo. A diminuição da concentração de ureia é observada quando há redução no consumo alimentar, especialmente com menor aporte de proteína, ou mínima mobilização das reservas proteicas (CALDEIRA et al., 2007). Foi exatamente o que ocorreu no presente estudo, devido à mínima mobilização de reserva proteica, pois embora tenham sido observados maiores valores de ureia no GT nos momentos M1, M2 e M3 ( $<0,040)$, apenas em M2, M3 e M4 os valores médios de ureia sérica do GC estavam inferiores aos considerados fisiológicos para ovinos, isto é, entre 2,86 e 7,14 mmol/L de nitrogênio ureico (KANEKO; HARVEY; BRUSS, 1997) ou então entre 6,21 e $15,52 \mathrm{mmol} / \mathrm{L}$ de ureia, indicando menor aporte proteico ou mínima mobilização de reservas para o GC nos momentos do parto e posteriores a ele.

A albumina foi inferior no GC em relação ao GT em M0 ( $\mathrm{P}=0,039)$, mas, com exceção do M2, onde os valores para as ovelhas dos dois grupos ficaram acima do considerado fisiológico para a espécie, isto é entre 24 e 30 g/L (KANEKO; HARVEY; BRUSS, 1997), nos demais momentos, além dos valores ficarem dentro da faixa fisiológica, não diferiram entre GC e GT. Como a primeira dose da vitamina só foi administrada após a coleta de sangue em M0, entende-se que ela não interferiu nas concentrações de albumina.

Em relação à creatinina, maiores concentrações foram observadas em GT nos momentos M2 e M4. A produção da creatinina é praticamente constante e está relacionada com o metabolismo da creatina, envolvida no fornecimento de energia para a massa muscular. Junto com a ureia, a creatinina é utilizada para monitorar a função renal. Sua excreção é afetada principalmente pela velocidade do fluxo urinário e não pela dieta. Os teores de creatinina ficam acima dos valores fisiológicos, à medida que ocorre a diminuição da taxa de filtração glomerular. Teores diminuídos de creatinina podem ser encontrados em condições de significativa redução na massa muscular. Esta condição não foi observada no presente estudo, já que além das ovelhas apresentarem concentrações de creatinina dentro dos valores considerados fisiológicos, entre 50 e $109 \mu \mathrm{mol} / \mathrm{L}$ (KANEKO; HARVEY; BRUSS, 1997), não foi observado aumento na concentração de ureia sérica, que é indicador de importante mobilização de massa muscular. A mobilização de proteína é um dos eventos envolvidos no mecanismo de lactogênese, cuja fonte principal de proteína é os aminoácidos mobilizados dos músculos esqueléticos, embora a involução uterina também possa contribuir neste sentido (BLUM et al., 1985; BELL; BURHANS; OVERTON, 2000).

A atividade de AST foi maior no parto (M2) para o GC. Este aumento de atividade poderia estar relacionado com a maior atividade da musculatura do útero no parto (BIRGEL JUNIOR; GRUNERT; STEFFEN, 1996), decúbito (SILVA et al., 2008) ou com aumento do metabolismo hepático (ANTUNOVIC et al., 2011), decorrente principalmente da mobilização de reservas corporais frequente neste período. Por não ter sido observado aumento na atividade da CK, e por não haver diferença no comportamento desta variável entre os grupos GC e GT, credita-se essa maior atividade de AST ao maior metabolismo hepático das ovelhas do GC em relação às do GT em M2, embora até mesmo neste momento os valores da AST tenham ficado dentro da amplitude considerada fisiológica (60 - 280 U/L; KANEKO; HARVEY; BRUSS, 1997). Essa diferença entre os grupos pode estar vinculada ao fato do GC ter apresentado tendência a maior número de fêmeas com gestação gemelar em relação ao GT $(\mathrm{P}=0,096)$, apesar de não ter havido diferença de peso entre os cordeiros nascidos. 
A enzima GGT apresentou maior atividade no GT, em M1 e em M2, o que pode estar vinculado à aplicação da vitamina $\mathrm{E}$, já que Araújo (2010), trabalhando com ovelhas vazias e gestando um, dois ou três fetos e Feitosa e Birgel (2000), acompanhando vacas holandesas no período periparto não observaram diferenças nas atividades de GGT em matrizes hígidas durante o período considerado. Ressalta-se ainda que, embora diferentes entre os grupos, em M1 e M2, as atividades permaneceram dentro da amplitude considerada fisiológica para os ovinos, isto é, entre 20 e 52 U/L (KANEKO; HARVEY; BRUSS, 1997) e que ficaram acima dos valores de referência, para ambos os grupos, nos momentos após o parto (M3, M4 e M5), devido à provável mobilização de reservas para a lactação.

A concentração sérica de colesterol foi maior no GT do que no GC apenas em M2 (P=0,041) e apesar desta diferença, é interessante observar que o teor de colesterol diminuiu para os dois grupos no parto. Piccione, Caola e Giannetto (2009) acompanharam o perfil bioquímico de ovelhas no diestro, início, meio e final da gestação; pós-parto; início, meio e final da lactação e período seco e também observaram diminuição nas concentrações de colesterol e triglicerídeos no final da gestação, pós-parto e início da lactação. A diminuição da concentração de colesterol observada em várias espécies durante a lactação em comparação ao diestro foi atribuída à absorção do colesterol pelos tecidos envolvidos na síntese de leite (NAZIFI; SAEB; GHAVAMI, 2002). Portanto, pode-se inferir que a menor diminuição do colesterol para o grupo tratado em relação ao controle pode ter ocorrido devido à melhor eficiência energética do primeiro para a síntese de leite.

O metabolismo oxidativo, no presente estudo, foi avaliado pelas atividades das enzimas antioxidantes superóxido dismutase (SOD) e glutationa peroxidase (GSH-Px), além da concentração de glutationa reduzida $(\mathrm{GSH})$ e da habilidade de redução do ferro plasmático (HRFP). De maneira geral, estes parâmetros estão relacionados ao perfil antioxidante.
A HRFP foi a única variável do metabolismo oxidativo, aqui considerada, que foi influenciada pela administração da vitamina E. As ovelhas do GT apresentaram maior HRFP uma semana após o parto (M3), o que significa que a suplementação parenteral com vitamina $\mathrm{E}$ proporcionou maior capacidade antioxidante em relação a não suplementação, especialmente no momento em que houve maior demanda energética (parto/lactação) e, portanto maior atividade metabólica destes animais. McDowell et al. (1992), observaram, em ovelhas, que o pico sérico da vitamina $\mathrm{E}$, após administração intramuscular, é de 9,8 h, e que a elevação das concentrações séricas permaneceram por tempo superior a $77 \mathrm{~h}$ após a aplicação. É interessante ressaltar que ao observarmos os coeficientes de variação $(\mathrm{CV})$ da HRFP nos momentos estudados notamos que no parto, momento onde esperávamos maior concentração de HRFP para as ovelhas tratadas, foi o momento que ocorreu maior $\mathrm{CV}$ para os animais do GC $(15,1 \%)$ e o terceiro maior CV para o GT (12,7\%). No M3 o CV foi o menor para os animais dos dois grupos e foi exatamente o momento onde conseguimos demonstrar o benefício da suplementação com a vitamina E. Os maiores CVs no GT foram observados respectivamente em M1 e M0 (26,1\% e 14,7\%). Como os efeitos da vitamina E são dose-dependente, outros estudos devem ser conduzidos com doses maiores desta vitamina. Mas deve-se ressaltar que importante limitação deste tipo de estudo é a data do parto, pois por mais que se saiba o exato momento da concepção, o parto pode antecipar ou atrasar, interferindo no tempo de ação no caso da vitamina, e aumentando o desvio padrão dos dados.

\section{Conclusão}

A suplementação parenteral com duas doses de 200 UI de vitamina E, com intervalo de duas semanas, no pré-parto, melhorou o metabolismo energético das ovelhas, especialmente quando considerados os resultados de AST, colesterol 
e da HRFP. Esta última refletiu o maior status antioxidante no grupo tratado, o que mostrou ser a suplementação um manejo positivo neste período da vida da fêmea quando o metabolismo oxidativo está aumentado.

\section{Referências}

ANTUNOVIC, Z.; NOVOSELEC, J.; SAUERWEIN, H.; SPERANDA, M.; VEGARA, M.; PAVIC, V. Blood metabolic profile and some of hormones concentration in ewes during different physiological status. Bulgarian Journal of Agricultural Science, Sofia, v. 17, n. 5, p. 687695, 2011.

ARAÚJO, C. A. S. C. Estudo comparativo do perfil metabólico e hormonal de ovelhas com gestação única, gemelar e não gestantes alimentadas com dieta de alta densidade energética. 2010. Dissertação (Mestrado em Ciências) - Faculdade de Medicina Veterinária e Zootecnia. Universidade de São Paulo, São Paulo.

BELL, A. W.; BURHANS, W. S.; OVERTON, T. R. Protein nutrition in late pregnancy, maternal protein reserves and lactation performance in dairy cows. The Proceedings of the Nutrition Society, Londres, v. 59, p. 119-126, 2000.

BENZIE, I. F.; STRAIN, J. J. The ferric reducing ability of plasma (frap) as a measure of "antioxidant power": the frap assay. Analytical Biochemistry, Philadelphia, v. 239, n. 1, p.70-76, 1996.

BERNABUCCI, U.; RONCHI, B.; LACETERA, N.; NARDONE, A. Markers of oxidative status in plasma and erythrocytes of transition dairy cows during hot season. Journal of Dairy Science, Madison, v. 85, n. 9, p. 2173-2179, 2002.

BEUTLER, E.; DURON, O.; KELLY, B. M. Improved method for the determination of blood glutatione. The Journal of Laboratory and Clinical Medicine, St Louis, v. 61, n. 5 , p. $882-888,1963$.

BIRGEL JUNIOR, E. H.; GRUNERT, E.; STEFFEN, S. Avaliação do perfil enzimático de bovinos da raça holandesa preta e branca durante as últimas 96 horas gestação. In: CONGRESSO BRASILEIRO DE MEDICINA VETERINÁRIA, 24., 1996, Goiânia. Anais... Goiânia: CBMV, 1996. p. 31-32.

BLUM, J. W.; REDING, T.; JANS, F.; WANNER, M.; ZEMP, M.; BACHMANN, K. Variations of 3-methylhistidine in blood of dairy cows. Journal of Dairy Science, Madison, v. 68, n. 10, p. 2580-2587, 1985.
CALDEIRA, R. M.; BELO, A. T.; SANTOS, C. C.; VAZQUES, M. I.; PORTUGAL, A. V. The effect of long-term feed restriction and over-nutrition on body condition score, blood metabolites and hormonal profiles in ewes. Small Ruminant Research, Amsterdam, v. 68, n. 3, p. 242-255, 2007.

CELI, P. The role of oxidative stress in small ruminants health and production. Revista Brasileira de Zootecnia, Viçosa, MG, v. 39, p. 348-363, jul. 2010. Suplemento.

DRACKLEY, J. K. Biology of dairy cows during the transition period: The final frontier? Journal of Dairy Science, Madison, v. 82, n. 11, p. 2259-2273, 1999.

DRÖGE, W. Free radicals in the physiological control of cell function. Physiology Reviews, Washington, v. 82, n. 1, p. 47-95, 2002.

GOFF, J. P.; HORST, R. L. Physiological changes at parturition and their relationship to metabolic disorders. Journal of Dairy Science, Madison, v. 80, n. 7, p. 12601268, 1997.

GRUMMER, R. R. Etiology of lipid-related metabolic disorders in periparturient dairy cows. Journal of Dairy Science, Madison, v. 76, n. 12, p. 3882-3896, 1993.

FEITOSA, F. L. F.; BIRGEL, E. H. Variação da concentração de imunoglobulinas $\mathrm{G}$ e $\mathrm{M}$, de proteína total e suas frações eletroforéticas e da atividade da gamaglutamiltransferase no soro sangüíneo de vacas holandesas, antes e após o parto. Arquivo Brasileiro de Medicina Veterinária e Zootecnia, Belo Horizonte, v. 52, n. 2, p. 111-116, 2000.

HALLIWELL, B.; GUTTERIDGE, J. M. Free radicals in biology and medicine. 4. ed. New York: Oxford University Press, 2007. 851 p.

HIDIROGLOU, M.; KARPINSKI, K. Vitamin E kinetics in sheep. British Journal of Nutrition, London, v. 58, n. 1, p. 113-125, 1987.

KANEKO, J. J.; HARVEY, J. W.; BRUSS, M. L. Clinical biochemistry of domestic animals. 5. ed. San Diego: Academic Press, 1997. 932 p.

LIMA, A. S. Metabolismo oxidativo, perfil bioquímico e função de polimorfonucleares de vacas holandesas primiparas e multiparas no periparto suplementadas com vitaminas ADE. 2013. Tese (Doutorado em Ciências) - Faculdade de Medicina Veterinária e Zootecnia. Universidade de São Paulo, São Paulo.

MCDOWELL, L. R.; WILKINSON, N. S.; NJERU, C. A.; LINDA, S. B.; WILLIAMS, S. N.; LENTZ, E. L. Serum alpha-tocopherol concentration in sheep after 
intramuscular injection of DL-alpha-tocopherol. Journal of Animal Science, Champaign, v. 70, n. 8, p. 2562-2567, 1992.

MILLER, J. K.; BRZEZINSKA-SLEBODZINSKA, E.; MADSEN, F. C. Oxidative stress, antioxidants, and animal function. Journal of Dairy Science, Madison, v. 76, n. 9, p. 2812-2823, 1993.

NAZIFI, S.; SAEB, M.; GHAVAMI, S. M. Serum lipid profile in iraninan fat-tailed sheep in late pregnancy, at parturition and during the post-parturition period. Journal of Veterinary Medicine A, Zurique, v. 49, n. 1, p. 9-12, 2002.

OLIVEIRA, D. R.; DOURADO, A. P.; CARDOSO, E. C.; BRANDÃO, F. Z.; ALMOSNY, N. R. P.; ALENCAR, N. X.; KÜHNER, J. S. O. Perfil metabólico de ovelhas da raça Santa Inês no período periparto criadas na baixada litorânea do estado do Rio de Janeiro: peso, condição corporal, volume globular e hemoglobinometria. Rio Grande do Sul: Sociedade Brasileira de Medicina Veterinária e Sociedade de Veterinária do Rio Grande do Sul, 2008. Disponível em: <http://www.sovergs.com.br/ conbravet2008/anais/cd/resumos/r0574-2.pdf $>$. Acesso em: 28 jan. 2010.

PICCIONE, G.; CAOLA, G.; GIANNETTO, C. Selected biochemical serum parameters in ewes during pregnancy, post-parturition, lactation and dry period. Animal Science Papers and Reports, Jastrzebiec, v. 27, n. 4, p. 321-330, 2009.
RIBEIRO, L.; GONZÁLEZ, F. Perfil metabólico de borregas Corriedale em pastagem nativa do Rio Grande do Sul. Acta Scientiae Veterinariae, Porto Alegre, v. 31, n. 3, p. 167-170, 2003.

SILVA, P. R. L.; COSTA, J. P. G.; SANTANA, A. M.; FAGLIARI, J. J. Perfil sérico das atividades das enzimas AST, GGT e ALP e das concentrações de ureia e creatinina de vacas leiteiras, repetidoras ou não de cio, durante a gestação e o pós-parto. Rio Grande do Sul: Sociedade Brasileira de Medicina Veterinária e Sociedade de Veterinária do Rio Grande do Sul, 2008. Disponível em: <http://www.sovergs.com.br/conbravet 2008/anais/cd/resumos/ R1240-3.pdf $>$. Acesso em: 28 jan. 2010.

STORILlO, V. M. Perfil metabólico de cabras submetidas a transporte rodoviário. 2012. Dissertação (Mestrado em Ciências) - Faculdade de Medicina Veterinária e Zootecnia. Universidade de São Paulo, São Paulo.

WEIGEL, R. A. Avaliação do metabolismo oxidativo e função renal de ovinos intoxicados por cobre e tratados com tetratilmolibdato e vitaminas antioxidantes. 2008. Dissertação (Mestrado em Ciências) - Faculdade de Medicina Veterinária e Zootecnia. Universidade de São Paulo, São Paulo. 
